





2015-10-01

\section{Studying the impact of intermittent variations using sensitivity analysis}

Khan, S.

British Institute of Non-destructive Testing

Khan, S., Phillips, P., Jennions I. (2015) Studying the impact of intermittent variations using sensitivity analysis, International Journal of Condition Monitoring, Vol. 5, Iss. 3, pp. 6-11 https://dspace.lib.cranfield.ac.uk/handle/1826/9992

Downloaded from Cranfield Library Services E-Repository 